\title{
La contratación electrónica: los supuestos «contratos informáticos» y los contratos celebrados a través de me- dios electrónicos
}

Carlos Alberto Soto Coaguila

\section{La revolución de las telecomunicaciones y el nacimiento de internet}

Hace aproximadamente diez años era un lujo tener una computadora. Recuerdo que como estudiante de una academia de computación tenía que formar largas colas para utilizar, por unos minutos, una computadora; era una época de los entonces novedosos lenguajes de programación: basic, dbasic, dbasic III plus, etc. Realmente era todo un reto utilizar una computadora ${ }^{1}$. Hoy las cosas han cambiado, pues aunque las computadoras todavía no están al alcance de todas las personas, un buen porcentaje, generalmente profesionales y estudiantes, tienen una computadora personal y el resto de la población puede acceder a ellas en las cabinas públicas. Un estudio del ALCA realizado en el Perú en mayo de 2000 determinó que en Lima 6 de cada 100 habitantes tenían una computadora personal ${ }^{2}$.

Otro suceso de enorme importancia en el Perú fue la masificación de los servicios telefónicos, lo que generó una revolución en el mundo de las telecomunicaciones. Antes de la década de los noventa, obtener una línea

1 La historia de las computadoras u ordenadores es sorprendente. En 1946 nació el primer computador electrónico comercial, llamado UNIVAC 1, el mismo que ocupaba el espacio de una gran habitación y, debido al calor que desprendían sus válvulas, requería de un sistema de refrigeración más grande que él mismo. Hoy tenemos computadoras personales del tamaño y dimensiones de un cuaderno y hasta menos.

2 Como hecho anecdótico, el gobierno peruano inauguró colegios escolares debidamente equipados con computadoras en lugares donde todavía no se contaba con energía eléctrica. 
telefónica era un auténtico lujo y un acto heroico. Un lujo por el altísimo costo que ello implicaba y un acto heroico por los largos años de espera. En la actualidad, tener un teléfono es como comprar cualquier producto de uso diario. Por si ello fuera poco, si uno compra un panetón navideño se hace acreedor a un teléfono móvil celular ${ }^{3}$.

En tercer lugar, cómo dejar de referirnos al avance tecnológico más importante del siglo XX: el internet, tecnología que también ha revolucionado el mundo de las telecomunicaciones, la información y los negocios, y su importancia en el desarrollo es tal que ha sido comparado con el invento de la imprenta por Gutemberg. Como sabemos, el internet tiene su inicio en EE.UU. en los años setenta cuando se llevó a cabo el proyecto militar denominado Advanced Research Projects Agency (ARPANet). Este sistema permitía la conexión de terminales o computadoras similares y fue diseñado para sobrevivir a un ataque nuclear. En los años ochenta, la agencia federal estadounidense National Science Foundation (NSF) empezó a expandir su red utilizando la tecnología de ARPANet con el objeto de conectar varias universidades y luego para enviar mensajes electrónicos. Recién en la década de los años noventa, y como consecuencia del enorme desarrollo de la industria de la computación en hardware y software, se hace posible el desarrollo del internet como medio para comunicarse y posteriormente realizar publicidad y hacer negocios a través de una computadora conectada directamente a la red de redes, mediante un módem con línea telefónica y un software de navegación ${ }^{4}$.

Recientemente, el 6 de diciembre de 2000, Jorge Kunigami, Presidente del organismo Supervisor de Inversión Privada en Telecomunicaciones

3 Durante la presentación del Presidente de OSIPTEL, Jorge Kunigami, ante la Comisión de Ciencia y Tecnología del Congreso de la República el 6 de diciembre de 2000, éste señaló: «En los NSE A y B, la tenencia de teléfono es de 96\%, de Computadoras 55\% y de conexión domiciliaria a Internet sólo $28 \%$. En el NSE C la tenencia de teléfono es $62 \%$, Computadoras $8 \%$ e Internet casi nulo. En los NSE D y E el $18 \%$ tiene teléfono, sólo $5 \%$ computadoras y $0 \%$ Internet. Esto refleja que el problema crítico pasa principalmente por el bajo índice en la tenencia de computadoras, especialmente en los NSE C, D y E; y por lo tanto bajo acceso a Internet. Por eso se desarrolla como alternativa las cabinas públicas.» (NSE significa Nivel Socio Económico).

4 Un informe de la Unión Internacional de Telecomunicaciones titulado «Desartollo Mundial de las Telecomunicaciones ańo 1996-1997", realizado en marzo de 1997, señala que en enero de 1997 había en el mundo 16 millones de computadoras y se calculaba entre 30 y 40 millones de usuarios de internet, por lo que en la actualidad podemos estimar que el número de usuarios supera los 60 millones. 
(OSIPTEL) se presentó ante la Comisión de Ciencia y Tecnología del Congreso de la República del Perú para manifestar que el Estado debía tener un rol proactivo en el desarrollo de internet y las Tecnologías de la Información en el país. Del mismo modo, precisó que se debía promover el desarrollo de medios de acceso (teléfonos fijo o móvil, tenencia de computadoras o televisión por cable), contar con diversas alternativas tarifarias, (a través de la introducción de nuevas tecnologías, planes tarifarios, tarifa plana), implementar un programa de educación y capacitación en esta materia, emitir y adecuar el marco regulatorio e impulsar el uso de estas tecnologías en las instituciones públicas. También manifestó que el número de usuarios de internet se ha triplicado desde 1998 y que actualmente se cuenta con más de 800,000 personas que acceden a internet a través de cabinas públicas y centros laborales (vía líneas dedicadas) o desde sus domicilios (acceso conmutado).

Sin lugar a dudas, la tecnología y la informática han naturalizado la globalización de tal forma que es completamente fácil informarse de todo lo está sucediendo en el mundo instantáneamente. Sin embargo, los medios informáticos y electrónicos nos pueden servir para realizar diferentes actividades, como almacenar información, comunicarse en cuestión de segundos y últimamente celebrar millones de contratos. Esta última actividad ha sido denominada como «e-commerce» o "comercio electrónico».

La temática que nos interesa, en este trabajo, es el nacimiento del llamado "comercio electrónico" o "e-commerce», el mismo que podemos definir como el conjunto de transacciones comerciales que se realizan virtualmente a través de la red de redes, es decir, por internet. En forma mucho más amplia se entiende por "comercio electrónico, al conjunto de transacciones comerciales y financieras realizadas por medios electrónicos, incluyendo texto, sonido e imagen. Es un sistema global que utilizando redes informáticas y en particular Internet permite crear un mercado electrónico (operado por computadora y a distancia) de todo tipo de productos, servicios, tecnologías y bienes e incluye todas las operaciones necesarias para concretar operaciones de compra y venta, matching, negociación, información de referencia comercial, intercambio de documentos, acceso a la información de servicios de apoyo (aranceles, seguros, transportes, etc.) y banking de apoyo; todo ello en condiciones de seguridad y confidencialidad razonables ${ }^{5}$.

5 Cfr. Ana I. Piaggi, «El comcrcio electrónico y el nuevo escenario de los negocios». En: 
Es sabido que para que las personas intercambien o adquieran bienes $\mathrm{y}$ servicios y en general realicen transacciones comerciales en forma lícita, como la compra de un CD, un libro, el periódico, un automóvil, cobre, frutas, entre otros, necesitan de un instrumento legal que se encuentre regulado por el ordenamiento jurídico, que los obligue y que, en caso de incumplimiento de una parte contratante, la otra pueda solicitar su cumplimiento y/ o la correspondiente indemnización por daños sufridos. Este instrumento no es otro que el contrato, definido por nuestro Código Civil en el artículo 1351 como el acuerdo de voluntades de dos o más partes destinado a crear, regular, modificar o extinguir relaciones juridicas patrimoniales.

En este contexto, surge la interrogante de si el contrato celebrado por medios electrónicos se encuentra dentro de los supuestos regulados por el Código Civil peruano o si requiere de reglas propias, distintas y especiales que le otorguen validez y eficacia. Dicho de otra manera, el punto a establecer es si esta nueva forma de contratar vía electrónica no altera las estructuras del derecho contractual vigente o por el contrario, rompe con los actuales paradigmas contractuales, siendo indispensable una reestructuración de la teoría general del contrato en el sentido de que la contratación ya no es nacional sino mundial y globalizada, lo que a su vez ha generado que el concepto de ley territorial en las transacciones internacionales por medios electrónicos pierda su plena vigencia.

Sin lugar a dudas, el auge cada vez más acelerado del comercio electrónico o e-commerce se ha masificado a tal extremo que se ha pronosticado que para el año 2003 el 25\% del comercio internacional se realizará por medios electrónicos y existirán alrededor de 300 millones de personas navegando en internet, por lo cual es necesario reflexionar en torno a los presupuestos sobre los que descansa la teoría contractual y determinar si ella soporta esta nueva forma de contratar, despersonalizada y virtual, o si por el contrario, resultan insuficientes y por lo tanto es indispensable construir o diseñar una nueva estructura contractual que permita o facilite el libre intercambio de bienes y servicios a través de internet.

Instituciones de Derecho Privado - Contratación Contemporánea dirigida por Atilio Aníbal Alterini, José Luis de los Mozos y Carlos Alberto Soto, Bogotá, Editorial Temis Palestra Editores, 2001, Volumen 2, p. 69. 


\section{El contrato: una visión dogmática y funcional}

\subsection{La estructura del contrato. Su objeto}

En sentido amplio, la ley es la única fuente de las obligaciones, pero para un importante sector de la doctrina son la ley y la voluntad.

Nosotros participamos de la tesis que señala que la única fuente inmediata y directa de las obligaciones es la ley y que el contrato es una fuente mediata de obligaciones, que a su vez tiene su fuente en la ley, pues es ésta la que permite a las personas autorregular sus intereses y garantiza que sus acuerdos sean válidos y exigibles.

Realizada esta precisión en torno a las fuentes de las obligaciones, diremos que el contrato es el acuerdo de voluntades de dos o más partes destinado a crear, regular, modificar, o extinguir relaciones jurídicas obligacionales de contenido patrimonial. Sin embargo, para que estas relaciones jurídicas sean válidas y exigibles no deben encontrarse fuera de los límites impuestos por el ordenamiento jurídico. En consecuencia, los acuerdos de las personas deben ser lícitos.

Ahora bien, el contrato tiene un objeto propio. Respecto al objeto del contrato existen tres posiciones. La tesis tradicional, según la cual el objeto del contrato es la prestación o prestaciones que emanan del contrato y que consisten en un dar, un hacer o un no hacer. La segunda tesis señala que el objeto del contrato es el bien o servicio materia del mismo; así, en el caso de una compraventa el objeto del contrato será la casa; en el mutuo, el dinero; en el contrato de obra, la construcción del edificio; etc. Estas posturas han sido adoptadas por el Código Civil argentino de 1871, que en su artículo $1.168^{\circ}$ señala que "Toda especie de prestación, puede ser objeto de un contrato, sea que consista en la obligación de hacer, sea que consista en la obligación de dar alguna cosa; y en este último caso, sea que se trate de una cosa presente, o de una cosa futura, sea que se trate de la propiedad, del uso, o de la posesión de la cosa»; y por el Código Civil español de 1889 , que en su artículo $1.271^{\circ}$ dispone que «Pueden ser objeto de contrato todas las cosas que no están fuera del comercio de los hombres, aun las futuras [...] Pueden ser igualmente objeto de contrato todos los servicios que no sean contrarios a las leyes o a las buenas costumbres".

La tercera tesis, esbozada por la doctrina moderna, sostiene que el objeto del contrato es la creación, regulación, modificación o extinción de 
obligaciones, es decir, de relaciones jurídicas obligacionales. Esta es la postura que ha adoptado el Código Civil peruano en el artículo $1402^{\circ} \mathrm{al}$ señalar que el objeto del contrato consiste en crear, regular, modificar o extinguir obligaciones.

En consecuencia, siguiendo al Código Civil peruano y a la doctrina autoral calificada, el contrato tiene por objeto la creación, regulación, modificación, transferencia o extinción de una relación juridica obligacional. Así, el contrato crea una relación juridica entre las partes contratantes, un vínculo jurídico entre acreedor y deudor, en virtud del cual el deudor tiene la obligación de ejecutar una prestación en favor del acreedor, quien a su vez tiene la facultad de exigirla.

Por su parte, la relación jurídica creada por el contrato también tiene un objeto propio, o mejor, un contenido distinto al del contrato. Este contenido es la prestación, que consiste en el comportamiento o conducta del deudor destinada a cumplir su obligación y que consiste en un dar, un hacer o un no hacer, tendiente a satisfacer el interés del acreedor.

Por último, la prestación, contenido de la relación jurídica, tiene su propio objeto, conformado por los bienes o servicios.

En síntesis, el contrato tiene por objeto la creación de una relación juridica entre los contratantes; la relación juridica tiene como contenido la/s prestaciónles que consiste/n en un dar, un hacer o un no hacer; $y$, la prestación/es tiene como objeto a los bienes o servicios.

Ejemplificaremos lo expresado en un contrato de compraventa entre Juan (vendedor) y Pedro (comprador). Cuando ambos contratantes deciden celebrar un contrato de compraventa de un inmueble y declaran su consentimiento, crean una relación jurídica obligacional, consistente en la obligación de Juan de entregar el inmueble y la obligación de Pedro de pagar el precio pactado. Pero, para que ambas partes cumplan con las obligaciones asumidas en el contrato de compraventa deberán ejecutar las prestaciones correspondientes (contenido de la relación jurídica); en este caso, Juan deberá entregar el inmueble o las llaves y Pedro pagar en efectivo el precio o depositarlo en una cuenta bancaria de ser el caso. Finalmente, el objeto de la prestación será el bien inmueble materia de la compraventa. 


\subsection{La clasificación de los contratos en nominados e innominados}

Otro tema que debemos precisar en el presente trabajo es el relativo a la regulación de las distintas categorías contractuales que bajo el rubro de "Contratos nominados" realiza el Código Civil peruano en la Sección Segunda del Libro VII destinado a las Fuentes de las Obligaciones.

Sobre la denominación de "Contratos nominados", manifestamos que no coincidimos con el codificador del '84 que siguió la vieja clasificación romana de los contratos en nominados e innominados, pues todos los contratos tienen un nomen juris, en consecuencia, no es propio referirse a los contratos como nominados e innominados, es preferible calificarlos como contratos típicos o atípicos ${ }^{6}$.

Un contrato será típico cuando se encuentre regulado específicamente en una ley, cualquiera que sea su naturaleza y no exclusivamente en el Código Civil. Contrario sensu, será atípico cuando carezca de una regulación legal específica. Al respecto, resulta apropiada la norma contenida en el Proyecto de Código Civil argentino de 1998, cuando en su artículo $913^{\circ}$ señala que «Los contratos son típicos o atípicos según que la ley los regule especialmente o no».

En este orden de ideas, el Código Civil peruano de 1984 regulaba diecisiete contratos típicos, pues hoy sólo quedan dieciséis, ya que la cláusula compromisoria y el compromiso arbitral han sido derogados con la dación de la Ley General de Arbitraje ${ }^{7}$. Estos dieciséis contratos regulados por el Código Civil no son únicos, pues existen otros contratos tipificados por el Código de Comercio ${ }^{8}$, la Ley General de Sociedades", la Ley Gene-

6 Esta la posición de la doctrina civilista y contractualista moderna. Sobre la regulación de los contratos atípicos, las normas aplicables recomendamos el trabajo de los profesores Atilio Aníbal Alterini y Roberto M. López Cabana, intitulado «Contratos Atípicos», en Instituciones de Derecho Privado - Contratación Contemporánea, dirigido por Atilio Aníbal Alterini, José Luis de los Mozos y Carlos Alberto Soto, Bogotá, Editorial Temis Palestra Editores, 2000, Volumen 1, pp. 351-367.

7 Originalmente fueron derogados por la Primera Disposición Final del Decreto Ley No 25935 del 10 de diciembre de 1992, y éste a su vez por la Ley No 26572 (nueva Ley General de Arbitraje) del 05 de enero de 1996.

8 Vigente desde 1902; regula los contratos de comisión mercantil, depósito mercantil, préstamo mercantil, prenda mercantil, contrato mercantil de transporte terrestre, contrato de seguro.

9 La Ley No 26887 regula a los contratos de asociación en participación y de consorcio de los artículos $438^{\circ}$ al $448^{\circ}$ inclusive. 
ral del Sistema Financiero y del Sistema de Seguros ${ }^{10}$, la Ley General de Minería ${ }^{11}$, el Reglamento de Tarjetas de Crédito ${ }^{12}$.

Si entendemos al contrato como un instrumento que permite el intercambio de bienes y servicios, o como diría Luis Diez-Picazo ${ }^{13}$ y Ricardo Lorenzetti ${ }^{14}$, un instrumento para la realización de actividades o relaciones económicas, es obvio que el universo contractual no se agota con los contratos típicos regulados por el Código Civil, ya que atendiendo al principio de la autonomía privada, las personas pueden celebrar cualquier contrato, típico o atípico, siempre y cuando su objeto sea lícito y, por tanto, no atente contra el orden público, las buenas costumbres o las normas legales de carácter imperativo. En tal sentido, el Código Civil peruano expresa en el artículo $1353^{\circ}$ que «todos los contratos de derecho privado, inclusive los innominados quedan sometidos a las reglas generales contenidas en esta sección, salvo en cuanto resulten incompatibles con las reglas particulares de cada contrato".

Coincidimos con Ricardo Lorenzetti, cuando advierte que el tipo contractual para «la teoría legal es un modelo que el legislador dispone para el uso de los contratantes» ${ }^{15}$, por lo tanto, tal como expresa Atilio Aníbal Alterini, «El amparo que la ley brinda al contrato que se subsume en el modelo que ella suministra (contrato tipico) incluye el otorgamiento al acreedor de los medios aptos para ejecutar las obligaciones resultantes» ${ }^{16}$. En consecuencia, si el legislador regula un contrato es porque lo considera necesario por diversas razones, ya porque su uso es masivo, porque está generando algunos inconvenientes en su interpretación, porque es necesa-

10 La Ley No 26702 regula los contratos de cuenta corriente (Art. 225\%), depósito de ahorros (Art. 229\%), prenda global y flotante (Art. 231\%), fideicomiso (241\%).

11 El Texto Único Ordenado de la Ley general de Minería (D.S. 014-92-EM) regula los contratos mineros de transferencia, de opción, de cesión minera, de hipoteca, de prenda, de riesgo compartido o joint venture.

12 Aprobada mediante Resolución de la SBS No 271-2000, regula los contratos de tarjeta de crédito.

13 Cfr. Diez-Picazo, Luis. «Masificación y contrato». En Daños, Buenos Aires, Ediciones Depalma, p. 11.

14 Cfr. Ricardo Luis Lorenzetti, Tratado de los Contratos. Buenos Aires, RubinzalCulzoni Editores, 1999, Tomo I, p. 19.

15 Cfr. Ricardo Luis Lorenzetti, Tratado de los Contratos. op. cit., Tomo I, p. 16.

$16 \mathrm{Cfr}$. Atilio Aníbal Alterini, Contratos. Civiles - Comerciales - De consumo. Teoría General. Buenos Aires, Abeledo - Perrot, 1999, p. 186. 
rio proteger a uno de los contratantes frente al poder económico de la otra parte, porque debe limitarse la autonomía privada de los contratantes; en síntesis, porque así lo exige la sociedad, la doctrina calificada y la jurisprudencia imperante. Sin embargo, no puede regularse un contrato por simple capricho legislativo, es necesario que la nueva figura contractual tenga un objeto y elementos propios, como lo tienen la compraventa, el arrendamiento, la donación, el suministro, etc., de lo contrario, tendríamos en el Código Civil o en las leyes especiales un glosario de contratos que muy bien pueden celebrarse sin la necesidad de una regulación legal específica, sino únicamente sobre la base de los dos grandes principios de la contratación privada: la autonomía privada y la buena fe contractual ${ }^{17}$.

Imaginemos si se regulan todas las nuevas formas de contratar o los llamados contratos modernos, necesitaríamos exclusivamente un Código para ellos. Por tanto, cabría preguntarse si es necesario e indispensable que se regulen. Gran parte de la doctrina cuestiona el hecho de pretender regular a los nuevos contratos, argumentando principalmente que todavía no han adquirido una madurez jurídica que justifique su regulación o que en algunos casos no se trata de categorías jurídicas independientes o autónomas; en suma, porque no hay una exigencia social, doctrinaria o jurisprudencial, que son las fuentes que determinarán la necesidad de regularlos. Esta es la posición de la vigente Comisión Reformadora del Código Civil de 1984 y la posición de la doctrina comparada calificada ${ }^{18}$.

A lo expresado debemos añadir que somos partidarios de dejar en libertad a las personas para que contraten, pero por supuesto dentro del marco legal impuesto por el Estado, como son el orden público, las bue-

17 Sobre la importancia de la autonomía privada y la buena en la contratación privada, se puede consultar nuestro trabajo La autonomía privada y la buena fe como fundamento de la obligatoriedad del contrato, publicado por el Colegio Público de Abogados de la Capital Federal Argentina, Buenos Aires, Cuadernos de Doctrina, Fascículo No 11, 2000.

18 Respecto a la regulación o no del contrato de franchising, Eduardo Benavides, expresa enfáticamente que «La franquicia lejos de necesitar códigos y barrotes necesita el oxígeno de un marco legal estable y un entorno económico de libre mercado, es en esto y no tan to en aquello en lo que deberían concentrar sus esfuerzos nuestras altas autoridades legislativas». (Cfr. Eduardo Benavides Torres, “Es necesario regular el franchising? Algunos comentarios más allá de los mitos y comentarios", en Revista Ius et Veritas, Revista editada por estudiantes de la Facultad de Derecho de la Pontificia Universidad Católica del Perú, Lima, Año VIII, No 15, p. 315). 
nas costumbres y las normas legales de carácter imperativo, o las limitaciones que se deriven del propio tráfico negocial ${ }^{19}$. Regular un contrato es muy peligroso, pues ello impide su diversificación, evita la creatividad contractual y comercial -propias del tráfico- y más aún, lo encasilla en modelos abstractos y normas rígidas muchas veces alejados de la realidad.

Pero, ¿cómo interpretar estas nuevas figuras contractuales o contratos atípicos?. Consideramos que, en primer lugar, deberá prevalecer la voluntad de las partes contratantes declarada y contenida en el contrato, y subsidiariamente aplicárseles las normas legales, empezando por las normas de la teoría general del contrato y luego las de los contratos típicos especiales. Desde luego, la interpretación de los contratos atípicos deberá efectuarse conforme al principio general de la buena fe que impone a los contratantes el deber de actuar conforme a Derecho y en forma leal y honesta en todas sus relaciones contractuales.

\section{Los supuestos «contratos informáticos»}

Habiendo delimitado el objeto del contrato y determinado la distinción entre contratos típicos y atípicos, así como la conveniencia de su regulación o no, estamos en condiciones de enfrentar uno de los temas centrales de nuestro trabajo, la existencia jurídica de los supuestos «contratos informáticos» o "contratos de informática».

El objetivo en este punto es determinar si existen jurídicamente, como categoría típica o atípica, los llamados «contratos informáticos» $\mathrm{y}$, de existir, precisar su objeto y sus elementos.

En forma casi unánime, un sector de la doctrina viene calificando a los contratos informáticos como una categoría contractual autónoma, es decir, como un contrato atípico que requiere, en la mayoría de ordenamientos, una regulación legal específica. Al respecto, señalaremos algunas definiciones esbozadas por esta doctrina.

En la doctrina española encontramos las siguientes definiciones:

Para María del Carmen Gete-Alonso Calera, los contratos informáticos son «aquellos cuyo objeto viene constituido por un bien (cosa) y/o por

19 Sobre las limitaciones de la autonomía privada ver Carlos Alberto Soto Coaguila, La autonomía privada y la buena fe como fundamento de la obligatoriedad del contrato, $o p$. cit., Fascículo No 11, pp. 8-15. 
un servicio informático" ${ }^{20}$. En igual sentido, Carrascosa López, Pozo Arranz y Rodríguez de Castro, sostienen que los contratos informáticos son aquellos que tienen por objeto los bienes y/o servicios relacionados con la informática ${ }^{21}$.

Precisando cuáles son los bienes y servicios informáticos, Eduardo Rodríguez de Castro, señala que el objeto de los contratos informáticos recae sobre bienes tales como el ordenador, el sistema de telecomunicación o la creación, confección y desarrollo de programas, y de servicios como el uso de equipos, la explotación de programas, la consulta a base de datos o archivos, el mantenimiento, la auditoría y la financiación ${ }^{22}$.

En la doctrina argentina también existen definiciones sobre los contratos informáticos.

En un fallo de la Corte Suprema de Mendoza la doctora Aída Kemelmajer de Carlucci ha manifestado, que los contratos informáticos con aquellos que tienen por objeto la prestación de bienes y servicios vinculados a la información automatizada ${ }^{23}$.

Claudia R. Brizzio define al contrato informático como aquél que tiene por objeto bienes o servicios informáticos. La autora precisa que los bienes informáticos son los elementos materiales que componen al hardware, su unidad de procesamiento, los periféricos, y todos los otros equipos que componen el soporte físico del elemento informático también forman parte de los bienes informáticos, los bienes inmateriales que proporcionan las órdenes, los datos, los procedimientos y las instrucciones en el procesamiento automático de la información. Respecto a los servicios informáticos,

20 María del Carmen Gete-Alonso Calera, La Ley, p. 1036, citada por Carlos Vattier Fuenzalida en su trabajo: En torno a los contratos electrónicos, en: Atilio Aníbal Alterini; José Luis de los Mozos, y Carlos Alberto Soto; Instituciones de Derecho Privado - Contratación Contemporánea, op. cit., Volumen 2, p. 19.

21 Cfr. Carrascosa López, V.; Pozo Arranz, Ma. A. y Rodríguez de Castro, E. P. La contratación informática: el nuevo horizonte contractual. Los contratos electrónicos e informáticos. Granada, Comares, 1997, p. 93.

22 Eduardo Rodríguez de Castro, Informática y derecho, citado por Carlos Vattier Fuenzalida, en su trabajo: «En torno a los contratos electrónicos», en: Atilio Aníbal Alterini; José Luis de los Mozos y Carlos Alberto Soto; Instituciones de Derecho Privado - Contratación Contemporánea, op. cit., Volumen 2, p. 19.

23 Citada por Graciela Messina de Estrella Gutiérrez, La Responsabilidad Civil en la Era Tecnológica. 2da. Edición, Buenos Aires, Abeledo-Perrot, 1997, p. 151. 
afirma, son aquellos que sirven de apoyo a la informática, tales como el diseño, el análisis y el mantenimiento del sistema ${ }^{24}$.

Ernesto Martorell y Jorge Bekerman son de la opinión que contratos informáticos «es una expresión que en doctrina denomina tanto a los contratos referidos a bienes y servicios informáticos como a los contratos celebrados entre computadoras» ${ }^{25}$.

En el Derecho chileno:

Magliona Markovith y Lopez Medel señalan que «existen dos tipos de contratos informáticos fundamentales: aquellos referidos a los bienes (equipos, periféricos, dispositivos, etc.) y aquellos referidos a los servicios (asistencia, formación, mantenimiento, programas, etc.) ${ }^{26}$.

Para Huerta Miranda y Libano Manzur, el objeto de los contratos informáticos, apriorísticamente, es la regulación de la actividad informática, precisando luego, sobre la base del Decreto Real Belga del 27 de abril de 1997, que los mismos recaen sobre: a) equipos físicos del sistema de tratamiento de la información (hardware), b) los equipos lógicos (software), y c) la actividad de asesoramiento informático ${ }^{27}$.

En nuestro medio, Max Arias-Schreiber Pezet ha escrito que no existe «un único tipo de contrato informático, sino más bien diferentes modalidades de contratación destinadas a uno u otro objeto relacionado con el ámbito de la informática» ${ }^{28}$. No obstante, el autor ha elaborado un «Anteproyecto sobre Contratos Especiales» destinado a regular los contratos informáticos ${ }^{29}$.

24 Cfr. Claudia R. Brizzio, "Contratos informáticos y contratos por medios informáticos». En: Atilio Aníbal Alterini, José Luis de los Mozos, y Carlos Alberto Soto; Instituciones de Derecho Privado - Contratación Contemporánea, op.. cit., Volumen 2, p. 82.

25 Cfr. Ernesto Eduardo Martorell, Tratado de los contratos de empresa. Buenos Aires, Ediciones Depalma, 1997, Tomo III, p. 637.

26 Cfr. Claudio Paúl Magliona Markovith, y Macarena Lopez Medel. Delincuencia y fraude informático. Derecho comparado y Ley No 19.223. Santiago de Chile, Editorial Jurídica de Chile, 1999, p. 29.

27 Cfr. Marcelo Huerta Miranda y Claudio Libano Manzur, Delitos Informáticos. Segunda edición complementada y actualizada a 1998. Santiago de Chile, Editorial Jurídica ConoSur Ltda., 1998, pp. 71-72.

28 Cfr. Max Arias-Schreiber Pezet, Contratos Modernos. Lima, Gaceta Jurídica Editores, 1999 , p. 318 .

29 Cfr. Max Arias-Schreiber Pezer, "Nuevos contratos en el Proyecto de Código Civil argentino», en El Código Civil del Siglo XXI. Perú y Argentina, obra coordinada por Jorge Muñiz; Atilio Alterini, y, Carlos Soto, Lima, Ediciones Jurídicas, 2000, Tomo I, pp. 812-813. 
Como podemos apreciar, los referidos autores conciben como una categoría autónoma y atípica a los contratos informáticos, exigiendo en algunos casos su regulación en el Código Civil o en una ley especial.

En principio, creemos que no es justo juzgar una opinión autoral a la luz de las reglas contractuales del derecho peruano, porque para el derecho peruano el objeto de los contratos es la relación jurídica obligacional mientras que para el derecho español y argentino el objeto del contrato son los bienes y servicios o las prestaciones.

En efecto, siguiendo la orientación de sus Códigos Civiles, los autores españoles y argentinos han definido a los contratos informáticos tomando en consideración:

a) Los bienes y servicios informáticos.

b) La supuesta novedad o complejidad de los mismos.

c) El desequilibro de información entre proveedores y clientes o usuarios.

d) El complicado lenguaje técnico del mundo de la informática.

Así, definen en forma unánime a los contratos informáticos como contratos atípicos cuyo objeto son los bienes y/o servicios informáticos.

No obstante, si se definiera a los contratos en atención a los bienes y/ o servicios, tendríamos un contrato por cada bien o servicio. Habría contratos madereros, de vegetales, de aves, de animales, aéreos, terrestres, inmobiliarios, médicos, de esoterismo, de sanación, manuales, eléctricos, de papelería, pesqueros, etc.; muchos de los cuales se distinguen por el bien o el servicio, o algunos por la complejidad.

Esto resulta ilógico jurídicamente, además de irrelevante. Definir u otorgar tipicidad social a un contrato en función al bien o servicio que se intercambia es por demás inadecuado. Por otro lado, sostener que los supuestos contratos informáticos tienen un cierto grado de complejidad contractual debido a la información asimétrica que existe entre los contratantes, es un hecho que afecta a todos los contratos y no en forma exclusiva a los supuestos contratos informáticos.

Del mismo modo, si un importante sector de la doctrina española, argentina, chilena y peruana califican a los contratos en función a los bienes y servicios, y desde luego a la complejidad que presentan, sin lugar a dudas, también deberían estar al lado de los supuestos contratos informáticos: los contratos médicos, que tienen infinidad de relaciones contractuales y su complejidad es notoria; los contratos de construcción, que van desde la construcción de una casa hasta una central hidroeléctrica; la subcontratación que genera más de un dolor de cabeza para los cons- 
tructores que han decidido solucionar sus problemas sobre la base de la autonomía privada y la buena fe contractual.

En síntesis, consideramos que los llamados contratos informáticos como figuras contractuales atipicas para el derecho peruano no existen juridicamente, ni mucho menos se puede pensar en regular esta categoría, porque no tienen un objeto propio y, peor aún, la complejidad que puede presentarse ante la información asimétrica es un problema de todo el sistema de contratación predispuesta o estandarizada.

No debemos olvidar que nosotros somos abogados o estudiantes de derecho, y no ingenieros, médicos o veterinarios ${ }^{30}$, por lo tanto, debemos referirnos con los términos propios de la Teoría General del Derecho al momento de calificar una u otra figura contractual. No podemos señalar que el contrato de compraventa tiene por objeto en el derecho peruano una casa, o que el contrato de suministro de energía eléctrica tiene por objeto la luz o los cables que sirven para su transmisión.

Pero, tampoco podemos negar que la informática está siendo de gran utilidad a la sociedad y que los bienes y servicios informáticos pueden ser susceptibles de tráfico patrimonial, pero como cualquier otro bien, estarán sujetos a las reglas propias de cada contrato que se celebren y, en su defecto, serán los contratantes quienes en ejercicio de su autonomía privada determinarán el contenido del contrato en atención a sus propios intereses. Por ejemplo, si se celebra un contrato de compraventa de computadoras, éste se sujetará, en primer lugar, a la autonomía privada de los contratantes y a las normas de carácter imperativo, y luego a falta de acuerdo entre las partes, se aplicarán supletoriamente las normas del contrato típico de compraventa y de la teoría general del contrato.

\section{IV.Contratos sobre bienes o servicios informáticos}

Como referimos al inicio del presente trabajo, la masificación de las computadoras personales y el crecimiento cada vez más acelerado de internet han generado el llamado "comercio electrónico o e-commerce», lo que a su vez ha dado origen, para un importante sector doctrinario, a los supuestos contratos informáticos.

Independientemente de nuestra posición de la inexistencia jurídica de los contratos informáticos como un contrato atípico, analizaremos los

30 En general, cualquier otro profesional que no sea abogado. 
bienes y servicios informáticos que pueden ser materia de distintos contratos típicos o atípicos.

Antes de abordar la contratación de estos bienes o servicios, es conveniente precisar qué entendemos por bienes informáticos y qué por servicios informáticos.

Los bienes informáticos son el hardware, conformado por el equipo físico para operar informáticamente; el software, conjunto de instrucciones que hacen posible el procesamiento de la información; $y$ la propiedad sobre los programas y datos, considerados como bienes incorporales o inmateriales.

Por su parte, los servicios informáticos pueden consistir en la educación, capacitación, actualización de información, limpieza de virus, auditorías y, en general, todo servicio que directa o indirectamente esté relacionado con los bienes informáticos.

Teniendo delimitados los bienes y servicios informáticos, nos preguntamos qué clase de contratos se pueden celebrar para intercambiarlos o adquirirlos. La respuesta es todos. Se puede celebrar toda clase de contratos típicos o atípicos, pero siempre que el contenido del contrato, es decir, su objeto no atente contra el ordenamiento jurídico y las limitaciones impuestas por él, como son el orden público, las buenas costumbres y las normas legales de carácter imperativo.

Entonces, se podrán celebrar contratos de compraventa, de cesión de derechos, de donación, de permuta, de suministro, de prestación de servicios, de obra, de arrendamiento, de franchising, de leasing, de fideicomiso, etc., y las reglas aplicables serán las establecidas por la voluntad de las partes contratantes, las normas imperativas establecidas por la ley para cada tipo contractual y luego, en forma supletoria, las normas legales de carácter dispositivo.

De la misma forma, de conformidad con el principio general de la buena fe contractual, contemplado en los artículos $168^{\circ}$ y $1362^{\circ} \mathrm{del}$ Código Civil peruano y, en general, por todos los ordenamientos jurídicos, los contratantes deben actuar conforme a Derecho y comportarse leal y honestamente en toda la fase previa a la contratación, es decir, mantener un comportamiento honesto y decente durante las tratativas o negociaciones, en la celebración del contrato y durante la ejecución de las respectivas prestaciones a que se encuentren obligados.

En el ámbito de las relaciones contractuales de consumo, el Estado tutela los derechos de los consumidores, derecho que tiene rango consti- 
tucional $^{31}$, señalando el artículo $65^{\circ}$ de la Constitución Política de 1993 , que los consumidores tienen derecho a la información de los bienes y servicios que se encuentran en el mercado. Ampliando este precepto, la Ley de Protección del Consumidor de 1991 - D. Leg. No 716 -, señala que los consumidores tienen, entre otros, los siguientes derechos (artículo $\left.5^{\circ}\right)$ :

a) A recibir de los proveedores toda la información necesaria para tomar una decisión o realizar una elección adecuadamente informada en la adquisición de productos y servicios, así como para efectuar un uso o consumo adecuado de los productos o servicios.

b) A la protección de sus intereses económicos, mediante el trato equitativo y justo en toda transacción comercial; y en la protección contra métodos comerciales coercitivos o que impliquen desinformación o información equivocada sobre los productos o servicios.

c) A la reparación por daños y perjuicios, consecuencia de la adquisición de los bienes o servicios que se ofrecen en el mercado o de su uso o de su consumo.

La citada Ley de Protección al Consumidor también expresa que los proveedores son responsables en las operaciones con consumidores (artículo $8^{\circ}$ ):

a) Por la idoneidad y calidad de los productos y servicios que ofrecen.

b) Por la autenticidad de las marcas y leyendas que exhiben los productos.

c) Por la variedad de la propaganda comercial de los productos.

d) Por el contenido y la vida útil del producto indicado en el envase.

Igualmente, se dispone en forma imperativa que los proveedores deberán informar a los consumidores o usuarios los casos en que no brindan el suministro oportuno de bienes y accesorios o servicios de reparación o mantenimiento de los bienes que producen, fabrican, ensamblan, importan, distribuyen o comercializan. Si no cumplen con informar estos hechos a los consumidores o usuarios en los contratos celebrados, están obligados, bajo responsabilidad, al oportuno suministro de partes y accesorios y al servicio de reparación o mantenimiento durante el lapso en que comercialicen los bienes o servicios en el mercado nacional y, posteriormente, durante un lapso razonable en función de la durabilidad de los productos (artículo $11^{\circ}$ ). 
La obligación de los proveedores en la prestación de servicios de reparación es mucho más específica, pues la Ley del Consumidor en el artículo $12^{\circ}$, dispone que los proveedores deben emplear componentes o repuestos nuevos y apropiados al bien de que se trate, salvo que el consumidor autorice expresamente y por escrito lo contrario.

En resumen, las normas nacionales sobre protección a los consumidores, que son muy parecidas en casi todos los ordenamientos jurídicos que cuentan una Ley del Consumidor, contienen normas que tutelan los derechos de los consumidores, así como normas imperativas que deben ser cumplidas por los proveedores. En consecuencia, ya existe un mecanismo de protección ante la adquisición de bienes o servicios que no reúnen las condiciones mínimas de calidad e idoneidad.

No obstante, este mecanismo de protección de los derechos del consumidor es territorial, es decir, se aplica a las relaciones de consumo dentro del territorio peruano, siendo además el organismo competente el Instituto Nacional de Defensa de Competencia y de la Propiedad Intelectual (INDECOPI). Así, cuando un consumidor o usuarios peruano adquiere un bien de un proveedor también peruano, se aplican las leyes peruanas; empero, el panorama se complica cuando las relaciones de consumo se dan entre proveedores y consumidores de diferentes países o, peor aún, cuando se contrata desde distintos países a través de medios electrónicos.

La respuesta no es fácil. Sin embargo, intentaremos desarrollar algunas ideas al respecto. Teniendo en cuenta que los bienes y servicios que adquieren los consumidores o usuarios se realizan bajo la forma de contratos predispuestos, es decir, los proveedores predisponen con anterioridad de la celebración del contrato las condiciones sobre las cuales comercializará sus bienes o servicios, para una adecuada protección de los consumidores, estas condiciones deberán ser aprobadas por una autoridad administrativa que tutele los derechos de los contratantes-consumidores. En el caso de las relaciones de consumo dentro del territorio peruano la autoridad administrativa podría ser el INDECOPI.

Pero si el consumidor adquiere los bienes y servicios por medios informáticos, y los proveedores se encuentran en otros países, y en el mundo virtual que crea internet, es decir, si se trata de contrataciones internacionales, el organismo que velará por la defensa de los consumidores debería ser la autoridad administrativa que en cada país defienda los derechos de los consumidores, la misma que se pondrá en contacto con su similar en 
el país donde se encuentre domiciliado el proveedor a efecto de presentar la denuncia correspondiente y accionar contra el proveedor, en virtud de que no podrá hacerlo desde el país del domicilio del consumidor.

En buena cuenta, en los contratos celebrados dentro del territorio peruano no existiría mayor problema para defender los derechos de los consumidores, pero en cambio, sí se pueden presentar algunos problemas en los contratos internaciones, los que desde luego pueden resolverse en forma creativa.

\section{Contratos celebrados a través de medios electrónicos}

El segundo aspecto fundamental de nuestro trabajo lo constituye la contratación electrónica, la contratación a través de medios electrónicos o la contratación por vía electrónica.

Decíamos que la masificación de internet ha generado el llamado comercio electrónico; sin embargo, para que las personas puedan adquirir o intercambiar los bienes y servicios que se ofrecen a través internet, se requiere de un instrumento jurídico: el contrato privado.

De otro lado, frente al naciente comercio electrónico, surge la interrogante de si estamos ante una nueva figura contractual, ante una nueva forma contractual o simplemente ante un uinstrumento tecnológico" que está permitiendo agilizar el tráfico negocial y reduciendo los costos de contratar o de transacción.

Antes de presentar nuestra posición será necesario referirnos brevemente al fenómeno de la contratación electrónica.

La aparición de la tecnología y la globalización han generado la llamada sociedad de la información, era de la información o era tecnológica. Con ella es necesario, como sostiene Ricardo Lorenzetti, repensar aspectos muy importantes de la sociedad relativos a la organización social, la democracia, la tecnología, la privacidad y la libertad ${ }^{32}$. Cabe recordar que en 1996 la Corte Suprema de los Estados Unidos ${ }^{33}$ brindó tutela constitucional a internet, señalando que es un paraíso democrático y que el gobierno debe protegerlo y no debe, por ningún medio, interrumpirlo. Esta Sentencia se expidió luego del intento del Presidente Clinton de

32 Cfr. Ricardo Luis Lorenzetti,. Tratado de los Contratos. op. cit., Tomo III, p. 833.

33 Cfr. Sentencia "Reno Attorney General of the United States et. Alv. American Civil Libertis Union et $A$ ), 521 US 44, 844. 
regular el contenido de la información que circula en internet con la finalidad de proteger a los menores.

Recordemos que internet es una red de redes que interconecta computadoras a nivel internacional y permite que cualquier persona pueda acceder a ella sin distinción de ninguna clase, salvo el costo económico que debe pagarse por su uso. Sus características pueden resumirse de la siguiente manera:

a) Es un medio de comunicación y de información para las personas.

b) Es una red abierta, porque cualquier persona puede acceder a ella.

c) Es interactiva, porque el usuario puede generar información y difundirla o intercambiarla, con lo cual se establecen relaciones.

d) Es internacional, porque trasciende las barreras nacionales o territoriales. En este sentido, internet brinda a las personas un medio eficiente y rápido para comunicarse. De allí que en la actualidad, entre sus múltiples funciones, sirva también como un medio para realizar transacciones comerciales, que pueden comprender, por ejemplo, desde la compra de un simple CD hasta transacciones multimillonarias como la adquisición de petróleo o minerales.

El comercio electrónico a través de internet permite una incomparable disminución de tiempo entre las comunicaciones, o más propiamente entre ofertas y aceptaciones; una notable reducción de los costos administrativos de los empresarios o proveedores que ya no requieren de establecimientos físicos, de personal, de sueldos para los vendedores, porque a veces es suficiente con un buen programa (software) para que el comercio se realice; un incremento sustancial de los ingresos por la venta de bienes o la prestación de servicios, ya que no existen horarios ni atenciones personalizadas, pues la informática permite programar las ventas en forma instantánea y automática, así la contratación por medios electrónicos, en su gran mayoría, son contratos predispuestos; porque existen incentivos en la reducción de los costos de transacción o de contratación; y, finalmente, la imposibilidad -hasta ahora- de gravar tributariamente a los bienes y servicios que se adquieren por internet.

Todos estos factores constituyen un enorme beneficio para proveedores y consumidores, porque estos últimos adquieren los bienes y servicios a un menor precio y sin pérdida de tiempo, y los empresarios o proveedores, al ofrecer a menores precios, realizan mayores ventas debido a que sus costos administrativos son bajos y todavía no existe una imposición fiscal. 
Pero, así como el comercio electrónico tiene grandes ventajas e incentivos, también presenta serios problemas de orden técnico y jurídico. Estos problemas están referidos a la seguridad en el envío de las comunicaciones y declaraciones contractuales (oferta y aceptación); la dificultad de la fiscalización tributaria por parte del Estado; el consentimiento que da vida al contrato y a la relación jurídica obligacional, pues no resulta fácil determinar el momento de la formación del contrato; ante la presencia de un conflicto, cómo determinar la legislación aplicable y la jurisdicción competente cuando las partes no han acordado la ley aplicable y los tribunales competentes, que podrían ser, por ejemplo, la Convención de Viena, la Cámara de Comercio de París, etc., respectivamente; el valor de los documentos electrónicos; los derechos de autor y de la propiedad intelectual; el derecho a la privacidad y a la información; los derechos de los consumidores y usuarios que adquieren bienes y servicios por internet; $y$, por último, la responsabilidad civil por los daños que a diario se ocasionan por internet, daños que van desde el envío de un virus, la difamación, la calumnia, así como todos los delitos informáticos que deben conllevar una sanción penal y una correspondiente reparación civil.

Estos son, en nuestra opinión, los problemas más relevantes y fundamentales, mas no los únicos, que el comercio electrónico está presentando en nuestros días y que los especialistas de la informática y los juristas no pueden ignorarlos, ya que deben atenderlos crítica, realista y funcionalmente.

En buena cuenta, las transacciones comerciales electrónicas han generado en más un jurista la necesidad de reflexionar en torno a las estructuras jurídicas vigentes a efecto de determinar si ellas solucionan $y$ permiten este tráfico negocial por internet o si se requiere de nuevas reglas.

\section{El «consentimiento» en los contratos celebrados a través de medios electrónicos}

Para que exista contrato, o mejor, para que nazca una relación jurídica válida se requiere que estén presentes todos los elementos esenciales del contrato y del acto jurídico como son: la plena capacidad de los contratantes, el consentimiento, el objeto física y jurídicamente posible, la finalidad lícita y, de ser el caso, la formalidad ad solemnitatem prescrita por ley bajo sanción de nulidad. 
Por su parte, el contrato es un acto jurídico plurilateral, un acuerdo de la voluntad común mediante el cual dos o más partes declaran su consentimiento para crear, regular, modificar, transferir o extinguir relaciones jurídicas obligacionales de carácter patrimonial.

Como podemos apreciar, el consentimiento es el alma del contrato, es el elemento fundamental que determina su existencia. Sin el consentimiento de ambos contratantes no existe el contrato y menos aun se crea una relación jurídica obligacional. El consentimiento es, pues, la declaración de la voluntad común de las partes contratantes, el momento de la coincidencia de la aceptación con la oferta.

Ahora, esta coincidencia de la aceptación con la oferta puede realizarse en forma inmediata o continuada. Por ejemplo, para la compraventa de un inmueble, el contrato puede formarse en forma instantánea si Juan hace la oferta y sin dilación de tiempo Pedro la acepta; o bien puede suceder que Juan le curse una carta ofreciéndole el inmueble a Pedro, concediéndole 10 días de plazo para que la acepte. En el primer supuesto no habrá problema alguno, pues el contrato se celebrará instantáneamente, pero en el segundo se presentan algunos inconvenientes, ya que surgen interrogantes de cuándo (momento) y dónde (lugar) se forma el contrato. De allí que tradicionalmente la doctrina distinga la contratación entre presentes y la contratación entre ausentes.

Desde antaño la doctrina y las legislaciones se han referido a los contratos entre ausentes y entre presentes, teniendo como eje principal la presencia física de los contratantes. Un contrato se celebraba entre presentes cuando se encontraban frente a frente cada una de las partes contratantes. En cambio, se concluía entre ausentes cuando mediaba distancia física entre ellos.

Antes de abordar cada una de estas formas de contratar, es necesario que realicemos algunas precisiones conceptuales en torno a los términos "presentes» $y$ «ausentes».

El término presente es aplicable a la persona que está en presencia del hablante, en el mismo lugar o momento que él, así como la circunstancia de encontrarse en un lugar determinado. Por su parte, ausente es el que está separado de alguna persona o lugar, especialmente de su residencia, siendo sus sinónimos lejano, distante.

Sin embargo, puede darse el caso, como en efecto ocurre, que dos personas se encuentren frente a frente y no puedan comunicarse en forma inmediata debido a razones idiomáticas o de salud (sordera, mudez, etc.); 
o que dos contratantes se encuentren en lugares distintos, Perú y China, y se comuniquen en forma instantánea a través del teléfono, fax, etc. En estos casos, los conceptos de presencia y ausencia no cumplen su finalidad, pues si la distancia física determina la existencia de un contrato, un contrato entre un ciudadano peruano y ciudadano chino que se entienden y se comunican por teléfono, y uno le vende su perro al otro sería considerado como un contrato entre ausentes; mientras que si los mismos contratantes, peruano y chino, en un ambiente físico deciden, el primero venderle su perro, pero el otro no lo entiende por la diferencia idiomática, además de no celebrarse el contrato debido a la falta de comunicación y entendimiento de ambos contratantes, en el caso de celebrarse podría ser calificado como un contrato entre presentes.

Por estas razones, el codificador de 1984 -como anota el profesor Manuel de la Puente ${ }^{34}$ - abandonó las nociones de contratación entre presentes y entre ausentes, para sustituirlos por los de comunicación inmediata y falta de comunicación inmediata, respectivamente, tal como puede apreciarse de la lectura del artículo $1385^{\circ}$ del Código Civil de $1984^{35}$.

Por lo tanto, los contratos serán de comunicación inmediata cuando la declaración contractual de un contratante es recibida por el otro en un lapso de tiempo razonable y mínimo, celebrándose el contrato en forma inmediata e instantánea. Y son contratos sin comunicación inmediata o a falta de ella, cuando exista dilación de tiempo u otorgamiento de plazos entre las declaraciones contractuales de los contratantes, generando que el contrato no se celebre en forma inmediata.

Ahora bien, referíamos que es importante determinar cuándo y dónde se forma el contrato, es decir, el momento y el lugar, pues ello determina-

34 Cfr. Manuel de la Puente y Lavalle, El contrato en general. Comentarios a la Sección Primera del Libro VII del Código Civil. Lima, Fondo Editorial de la Pontificia Universidad Católica del Perú, 19993, Tomo II, p. 250.

35 El artículo $1385^{\circ}$ del Código Civil de 1984 expresa: «La oferta caduca:

1.- Si se hizo sin conceder plazo determinado o determinable a una persona con la que el oferente está en comunicación inmediata y no fue seguidamente aceptada.

2.- Si se hizo sin conceder plazo determinado o determinable a una persona con la que el oferente no está en comunicación inmediata y hubiese transcurrido el tiempo suficiente para llegar la respuesta a conocimiento del oferente, por el mismo medio de comunicación utilizado por éste.

3.- Si antes de recibida la oferta o simultáneamente con ésta llega a conocimiento del destinatario la retractación del oferente.» (El énfasis es nuestro). 
rá desde qué momento las partes están vinculadas contractualmente y, por ende, obligadas a ejecutar sus prestaciones; y en segundo lugar, dónde se formó en contrato, el lugar de formación del contrato, a efecto de poder determinar la legislación aplicable y la jurisdicción competente. Desde luego, las partes contratantes tienen la libertad para acordar una legislación aplicable y una jurisdicción competente distinta, pues en ejercicio de su autonomía privada son libres para pactar las leyes y tribunales que convengan a sus intereses.

$\mathrm{Al}$ respecto, la doctrina ha elaborado cuatro teorías sobre la formación del contrato. Estas teorías son: de la declaración, de la expedición, de la recepción y del conocimiento. Veamos brevemente cada una de ellas.

a) La teoría de la declaración: Es la teoría más simple, también llamada como de la manifestación. Según esta teoría el contrato se forma cuando el aceptante manifiesta o declara, es decir, exterioriza, su aceptación de celebrar el contrato conforme a los términos y condiciones de la oferta.

b) La teoría de la expedición: De acuerdo con esta teoría no es suficiente que el aceptante declare o manifieste su aceptación, sino que será necesario que se desprenda de ella, es decir, que la envíe, la dirija hacia el oferente y por lo tanto deje de controlarla.

c) La teoría de la recepción: Según esta teoría, el contrato se forma cuando la aceptación llega a la dirección, al domicilio del oferente, no siendo necesario que el oferente se entere de su contenido, pues basta que llegue fehacientemente la aceptación al ámbito de acción o esfera jurídica del oferente. Esta es la teoría más aceptada en la doctrina comparada y legislación mundial.

d) La teoría del conocimiento: Conocida también como teoría de la cognición o de la información. De acuerdo con esta teoría el contrato se forma cuando el oferente conoce la aceptación de su oferta, con lo que se da la coincidencia de las declaraciones de voluntad, surgiendo en consecuencia, el consentimiento o voluntad común de ambos contratantes.

Cada una de estas teorías tiene sus defensores y detractores, sus pro y sus contra, que no es el momento de analizar.

Aplicando las diversas teorías sobre la formación del contrato a cada una de las formas de contratar (contratación con comunicación inmediata y contratación sin comunicación inmediata), diremos que en la contratación con comunicación inmediata no hay problema alguno, pues el contrato se forma de inmediato, instantáneamente, por lo que resulta 
innecesario recurrir a una u otra teoría, ya que si los dos contratantes están en comunicación inmediata importa poco si se forma el contrato cuando Pedro le dice "acepto" a Juan (declaración), cuando Pedro se desprende del «acepto» a través de palabras o mediante un fax (expedición), cuando Juan recibe el «acepto» (recepción), o cuando Juan conoce y comprende el "acepto", ya que en cualquiera de los casos se forma el contrato instantáneamente. En este supuesto, los cuatro momentos se dan en forma simultánea.

En cambio, el problema se presenta cuando estamos frente a la contratación donde los contratantes no están en comunicación inmediata, ya que es distinto si el contrato se forma cuando el contratante peruano decide aceptar la oferta del contratante chino, cuando deposita su aceptación contenida en una carta en el buzón de correo, cuando el contratante chino recibe la carta que contiene la aceptación del contratante peruano o cuando el contratante chino conoce la aceptación porque ha leído la carta. En estos supuestos, es evidente que existe un problema, ya que resulta impreciso saber cuándo se formó el contrato, el lugar de su formación y lo más importante desde cuándo están obligados cada uno de los contratantes.

Esto no es pura dogmática jurídica. Determinar el momento y lugar de la formación del contrato es sumamente importante, ya que por ejemplo, ante un posible incumplimiento o daño que un contratante cause al otro deberá determinarse qué tipo de responsabilidad debe aplicarse, la responsabilidad contractual o extracontractual, pues si todavía no hay contrato entonces las reglas aplicables serán las de la responsabilidad civil extracontractual. Los ejemplos serían innumerables. Imaginemos que el contratante chino, en aplicación de la teoría de la expedición, cree que ya se concluyó el contrato y deposita el dinero de la compra de la casa, pero el contratante peruano que de acuerdo a la teoría de la recepción no ha recibido aceptación alguna vende la casa. ¿Cómo resolvemos el conflicto?. Más aún, es fundamental saber el momento de la formación del contrato para determinar la ley aplicable en el tiempo, la ley vigente, referida, por ejemplo, a la licitud del objeto, lo que hoy es ilícito mañana puede no serlo y a la inversa; los plazos señalados a fin de que empiecen a computarse; la capacidad de ejercicio de las partes; etc.

Sobre la formación del contrato, cada país ha optado por una regla propia en función de considerarla la más apropiada. Así, en Argentina se forma el contrato, según el artículo $1.154^{\circ}$, siguiendo la teoría de la expe- 
dición; en España, en el artículo $1.262^{\circ}$ se sigue la teoría del conocimiento; en el derecho peruano, que ha seguido muy de cerca el Código Civil italiano de 1942, el contrato se forma, en aplicación del artículo 1373, cuando el oferente conoce la aceptación plena de su oferta. $Y$ ¿cuándo conoce la aceptación el oferente y cuándo el aceptante sabe que su aceptación ha llegado a conocimiento del oferente? El Código Civil peruano en el artículo $1374^{\circ}$ establece que todas las declaraciones contractuales (oferta, aceptación, contraoferta, etc.) se consideran conocidas cuando llegan a la dirección/domicilio del destinatario, salvo prueba en contrario. Es decir, se presume (juristantum) que con la recepción se da el conocimiento.

Una vez determinado el momento de la formación del contrato en el derecho peruano, debemos responder a la segunda interrogante, dónde se forma el contrato, es decir, el lugar de formación del contrato.

En el caso de contratos con comunicación inmediata sabemos que ambos contratantes pueden estar físicamente en el mismo lugar como pueden estar en lugares distintos. En el primer supuesto, el contrato se formará en el lugar en que se encuentren ambos contratantes, y en el segundo supuesto, en el lugar donde se encuentre el oferente.

En la contratación sin comunicación inmediata, de acuerdo con el artículo $1373^{\circ}$ del Código Civil peruano, los contratos se forman «en el momento y lugar en que la aceptación es conocida por el oferente", y en aplicación del artículo $1374^{\circ}$ que complementa el artículo $1373^{\circ}$, la aceptación se considera conocida en el momento en que llega a la dirección del destinatario; pero ningún artículo dice nada respecto al lugar de formación del contrato, por lo que a nuestro entender y siguiendo la doctrina peruana, consideramos que el contrato se formará en el lugar del domicilio del oferente, independientemente de que éste conozca la aceptación en otro lugar distinto a su domicilio. Por ejemplo, si Juan vive en Lima y de ahí realiza una oferta a Pedro que vive en Arequipa, el contrato se formará cuando la aceptación de Pedro llegue al domicilio de Juan en Lima, salvo que Juan pruebe que estuvo en la imposibilidad de conocer la aceptación de Pedro.

Un sector minoritario de la doctrina considera que el contrato se forma en el lugar en que el oferente conoce la aceptación, lugar que puede ser distinto a su domicilio. Retomando el ejemplo anterior, si Juan está de viaje en Chiclayo y su secretaria le envía por fax la aceptación que remitió Pedro a su domicilio en Lima, el lugar del contrato será Chiclayo y no Lima. Esta solución no ha sido adoptada por el legislador peruano. 
Como podemos apreciar, las normas de la teoría general del contrato sirven para poder determinar el momento y lugar de la formación del contrato, es decir, la formación del consentimiento que crea el contrato y éste la relación jurídica obligacional.

El problema se presenta cuando los contratantes son de distintos países teniendo cada uno de ellos su propia legislación. Imaginemos el siguiente caso: Un contratante peruano envía una oferta a un vecino argentino ofreciéndole venderle cien toneladas de lana de alpaca, el día 05 de mayo de 2001. Suponiendo que las cartas entre Perú y Argentina demoran cinco días en llegar, la carta que contiene la oferta y que tiene una vigencia de quince días es recibida por el contratante argentino el día 10 de mayo. El contratante argentino envía su aceptación el día 19 de mayo, llegando tal declaración contractual al domicilio del contratante peruano el día 24 de mayo. Pero, el contratante peruano, el 22 de mayo vende las cien toneladas a un comerciante chileno, ya que hasta la fecha no recibió respuesta alguna de su colega argentino y la oferta caducó según el derecho peruano. Supongamos que en este contrato las partes contratantes no fijaron ni la legislación aplicable ni la jurisdicción competente, como podría ser la Convención de Viena que regula la Compraventa Internacional de Mercaderías, se olvidaron, la obviaron. ¿Qué ley aplicamos, la argentina, la peruana o la internacional?, ¿¿uándo se formó el contrato?, ¿dónde se formó el contrato?. Estas son las preguntas claves y en torno a las cuales intentaremos algunas respuestas.

Si aplicamos la legislación peruana el resultado es el siguiente:

a) La oferta caducó el día 20 de mayo.

b) No se formó contrato, pues la aceptación llegó tardíamente, el 22 de mayo.

c) El contratante peruano, en todo su derecho, vendió legalmente su lana de alpaca.

Si aplicamos la legislación argentina el resultado es distinto:

a) Si se formó contrato desde el momento que el contratante argentino expidió su aceptación el día 19 de mayo, fecha en que estaba vigente la oferta.

b) El contratante argentino reclamará la entrega de las cien toneladas de alpaca y solicitará la indemnización de daños y perjuicios de ser el caso. Aplicando el derecho internacional de cada país, la situación se complica mucho más. Según el derecho internacional privado regulado por el Código Civil peruano, las reglas son las siguientes: 
a) El artículo $2047^{\circ}$ establece con carácter imperativo una prelación de normas a aplicarse en caso de conflicto de derecho aplicable para regular relaciones jurídicas con ordenamientos extranjeros. Esea prelación es la siguiente:

i) En primer lugar, se debe recurrir a los Tratados Internacionales ratificados por el Perú.

ii) En segundo lugar las normas de Derecho Internacional Privado del Código Civil peruano de 1984, y

iii) En tercer lugar, los Principios Doctrinarios del Derecho Internacional Privado ${ }^{36}$.

b) El artículo $2095^{\circ}$ señala que las obligaciones contractuales se rigen:

i) Por la ley expresamente elegida por las partes, o en su defecto,

ii) Por la ley del lugar de su cumplimiento (de su ejecución),

iii) Si no fuese posible determinar el lugar del cumplimiento (contrato sinalagmático), pues deben cumplirse en países distintos, se rigen por la ley de la obligación principal (en un contrato de compraventa donde se entrega el bien),

iv) Si no es posible lo anterior, se aplica la ley del lugar de celebración del contrato.

Pero el derecho argentino también tiene sus propias reglas de derecho internacional privado. ¿Qué ley aplicamos?

Y nótese que hasta aquí no hemos dicho nada sobre los contratos celebrados por medios electrónicos, estamos en la contratación privada pura y simple.

En la contratación tradicional, sin lugar a dudas son los contratantes los que se encuentran en la mejor situación de poder establecer la ley aplicable al contrato que van a celebrar. Al respecto, Delia Revoredo de Mur, comentando el artículo $2095^{\circ}$ del Código Civil peruano señala que:

"[...] es de suponer que nadie se obliga si no es conforme con una ley que conoce, y la ley común para ambas partes, más probablemente

36 Cfr. Delia Revoredo, (Comp.). Código Civil. Exposición de Motivos y Comentarios. Lima, OKURA Editores S.A., 1985, Tomo VI, p. 897. En la Exposición de Motivos del Libro de Derecho Internacional Privado a cargo de la Dra. Delia Revoredo, señala que la aplicación del artículo $2047^{\circ}$ es imperativa y las partes no pueden sustraerse de su aplicación. 
conocida por ellas, es la del lugar de la celebración, por ser la que con mayor facilidad pudieron conocern ${ }^{37}$.

No cabe la menor duda que esto funciona cuando los contratantes, peruano y argentino, contratan paritariamente, es decir, negocian el contenido del contrato y en base a su autonomía privada determinan no sólo el contenido del contrato, sino también la legislación aplicable a la relación jurídica que están creando por el contrato y la jurisdicción competente en caso de presentarse algún conflicto de interpretación o en caso de incumplimiento.

Empero, esto no funciona en el caso de la contratación predispuesta, masiva o estandarizada, donde los contratantes son anónimos y donde uno de los contratantes, normalmente el empresario o proveedor, predispone o elabora unilateralmente el contenido del contrato. Seguramente se dirá que los predisponentes incorporarán cláusulas expresas sobre la legislación y la jurisdicción aplicable; pero si no lo hacen, seguimos con el mismo problema.

Regresando al objeto de nuestro trabajo, es decir, cómo funciona la contratación a través de medios electrónicos y qué legislación se aplica, podemos afirmar lo siguiente:

Luego de haber reflexionado en torno a la contratación privada que se realiza en forma tradicional, por carta, por fax, por teléfono, consideramos que no existe ninguna diferencia sustancial con la contratación realizada a través de otros medios electrónicos, por medios informáticos o por vía electrónica.

Nos explicamos.

En primer lugar, debemos precisar que la manifestación de voluntad es uno de los requisitos de validez del acto jurídico, diríamos de existencia, pues sin él no existiría el acto jurídico, lo cual hace que también sea un requisito de validez del contrato, por lo que cada contratante debe manifestar o declarar su voluntad de contratar, mediante la oferta y la aceptación. De conformidad con el artículo $140^{\circ}$ y $141^{\circ}$ la manifestación de voluntad puede ser expresa o tácita. Es expresa cuando se for-

37 Cfr. Delia Revoredo (Comp.). Código Civil. Exposición de Motivos y Comentarios. op. cit., Tomo VI, p. 1013. 
mula oralmente o por escrito, y es tácita cuando la declaración de voluntad se infiere indubitablemente de una actitud o de circunstancias de comportamiento.

Al respecto, la Comisión de Reforma de Códigos del Congreso de la República presidida por Jorge Muñiz Zíches, presentó un Proyecto de Ley para modificar el Código Civil, el mismo que fue aprobado mediante la Ley No 27291 el 24 de junio de 2000. La modificación tenía por finalidad posibilitar que la manifestación de voluntad pueda realizarse a través de medios electrónicos $\mathrm{u}$ análogos y, por tanto, tenga la misma validez y eficacia que cualquier manifestación de voluntad tradicional (carta, fax, etc.)

No obstante, desde una perspectiva dogmática y sistémica, el artículo $141^{\circ}$ del Código Civil, tal como se encontraba antes de su modificación era muy amplio al señalar que la manifestación de voluntad es expresa "cuando se formula oralmente, por escrito o por cualquier otro medio directo", supuesto dentro del cual consideramos que se encontraban las diversas formas expresas de manifestación de voluntad, la misma que podía realizarse por teléfono, fax, videoconferencia, telex, correo electrónico, chat, cable, señales de humo, etc.

Desde luego, la modificación al Código Civil tampoco perjudica la manifestación de voluntad expresa, muy por el contrario la precisa, la detalla y la enuncia en forma -valga la redundancia- expresa, con lo cual no queda la menor duda de que las manifestaciones de voluntad emitidas por medios electrónicos u otros análogos son válidos y eficaces.

Sin embargo, nos preguntamos si las normas deben ser reglamentos o por el contrario deben contener supuestos generales, normas fundamentales y sobre la base de ellas, el juez, el magistrado o el abogado, deben interpretar las normas y crear el Derecho. Preferimos que el legislador asuma una función creadora del Derecho y no que cada vez que exista alguna novedad se deba precisarla o detallarla recurriendo a una modificación civil. No me opongo a las reformas, pero soy partidario de la función creadora de los juristas, magistrados y abogados. Parafraseando el refrán del pescador, diríamos que debemos enseñar a pescar, a interpretar y no entregar pescado o normas reglamentarias a los operadores del Derecho.

En suma, actualmente el Código Civil peruano regula en forma expresa que la manifestación de voluntad puede realizarse a través de medios electrónicos y éstas son totalmente válidas y eficaces. 
Entonces, no existe impedimento para que las personas puedan contratar por medios electrónicos, ya sea utilizando el chat o el correo electrónico (e-mail).

Así, la contratación por medios electrónicos puede realizarse con comunicación inmediata y sin comunicación inmediata, por lo que los contratos celebrados por está vía pueden ser contratos entre ausentes o entre presentes, respectivamente.

La contratación con comunicación inmediata será aquella contratación mediante el llamado chat o incluso por el sistema de correo electrónico permanente, pues en ambos casos los contratantes estarán en comunicación inmediata, lo que permitirá que se forme instantáneamente el contrato. En cambio, la contratación será sin comunicación inmediata a través de medios electrónicos cuando exista dilación de tiempo o plazos en la formación del contrato.

Hasta aquí todo es igual en relación a cualquier contrato celebrado por otro medio como el fax, el télex o el teléfono.

El fenómeno del comercio electrónico genera complejidad cuando nos damos cuenta que en internet no existe un contratante determinado, es decir, existe una despersonalización de los contratantes y, por otro lado, no existe una ubicación espacial o territorial de los contratantes, como diría Alfredo Bullard, se presenta una llamada desgeografización en la ubicación de los contratantes.

En este contexto, es el momento de preguntarnos si se aplican las reglas de la contratación privada regulada por el Código Civil de 1984 a la contratación por medios electrónicos o se requiere de otras normas específicas.

En principio, no hay impedimento alguno para aplicar las reglas del derecho común (regulados por el Código Civil, complementado por otras leyes como la ley de Defensa del Consumidor, el Código de Comercio, etc.) a las relaciones contractuales creadas por medios electrónicos. Si recordamos el artículo $1373^{\circ}$ del Código Civil peruano, el contrato se forma en el momento y lugar que el oferente conoce la aceptación, y conforme al artículo $1374^{\circ}$ del Código Civil peruano, se considera conocida la aceptación cuando ésta llega al domicilio del oferente. En el caso de una carta, probar su recepción en el domicilio no hay problema, pues para ello existe la constancia del correo o mensajería, en el caso del fax, tenemos el cargo de envío que nos proporciona la máquina de fax, pero en la contratación por medios electrónicos como el correo electrónico, cómo saber cuándo ha llegado un correo al domicilio del otro contratante a efecto de 
aplicar la presunción juris tantum contenida en el artículo $1374^{\circ}$ del Código Civil.

Para salvar este inconveniente, así como el fax tiene una constancia que automáticamente nos indica que el documento se envió conforme, el número de hojas, la hora, fecha, etc., en el correo electrónico también es posible utilizar un servicio automático de envío y recepción de mensajes. Para el sistema de envío de correos electrónicos no tenemos problema alguno, pues el remitente tendrá en su archivo de documentos enviados los datos de envío de su declaración contractual y para saber cuándo llegó a su destinatario y además cuándo conoció su oferta o su aceptación, existe un sistema electrónico conocido como el «acuse de recibo».

$\mathrm{El}$ «acuse de recibo» es un sistema tecnológico que puede ser activado automáticamente en los correos electrónicos. Mediante este sistema de "acuse de recibo», es posible determinar con exactitud cuándo un mensaje de datos conteniendo una oferta o una aceptación está siendo abierto y por ende conocido por el destinatario. Así, con este sistema podemos saber con exactitud no sólo cuándo ha recibido la aceptación el oferente, sino también cuándo la ha conocido, con lo cual puede operar la presunción de conocimiento que exige el artículo $1374^{\circ}$ del Código Civil peruano y entonces formarse el contrato válidamente. No obstante, debemos precisar que el «acuse de recibo» no puede ser cualquier acuse de recibo, sino aquél que establezca en forma indubitable que el mensaje está siendo leído por el destinatario en su servidor.

Esta ha sido la solución que la Comisión de Reforma de Códigos, mediante la Ley No. 27291, introdujo al Código Civil de 1984 en el artículo $1374^{\circ}$ como segundo párrafo, al señalar:

«La oferta, su revocación, la aceptación y cualquier otra declaración contractual dirigida a determinada persona se consideran conocidas en el momento en que llegan a la dirección del destinatario, a no ser que éste pruebe haberse encontrado, sin su culpa, en la imposibilidad de conocerla.

Si se realiza a través de medios electrónicos, se presumirá la recepción de la aceptación y cualquier otra declaración contractual dirigida a determinada persona, cuando el remitente reciba acuse de recibo."

Como podemos apreciar, el legislador peruano ha optado por ampliar la presunción de conocimiento de la declaración contractual de acepta- 
ción, oferta u otra, cuando el remitente reciba en su computadora el respectivo "acuse de recibo", el cual determinará que el destinatario ha abierto su buzón de correo y está leyendo el mensaje y, por tanto, ha conocido la declaración contractual, que contiene el mensaje electrónico.

Otro aspecto a desarrollar es el relativo a la presunción de conocimiento juris tantum que contempla el artículo $1374^{\circ}$, al establecer que el destinatario puede oponer el conocimiento de la declaración contractual cuando sin su culpa estuvo imposibilitado de conocer el contenido, por ejemplo, de la aceptación, con lo cual no se habrá celebrado ni perfeccionado el contrato. Por ejemplo, si en un contrato celebrado por carta la aceptación llega un determinado día en el cual el oferente se encuentra internado de emergencia en un hospital, desde luego, estará imposibilitado de conocer tal aceptación y podría oponerse a la formación del contrato, en virtud de que la presunción de conocimiento es juris tantum y no juris et de jure.

Ahora, en la contratación por medios electrónicos, debemos establecer si también debe admitirse la presunción juris tantum o si por el contrario ésta debe ser del tipo juris et de jure. Esto es relevante, pues si con el sistema de acuse de recibo se presume el conocimiento de la aceptación (u otra declaración contractual) sería factible que el destinatario -el oferente en este caso- se oponga a la formación del contrato cuando sin su culpa no pudo conocer tal aceptación, ya que de no abrir el oferente su correo electrónico, el aceptante nunca recibiría ningún acuse de recibo. Para Rolando Castellares, esta presunción debe ser juris et de jure, vale decir, que el oferente no podría oponerse a la formación del contrato en ningún caso. Si bien es cierto que la presunción que no admite prueba en contrario confiere cierta seguridad jurídica, por otro lado, consideramos que el tema presenta algunos problemas, pues así como sujetos inescrupulosos pueden interceptar las cartas físicas, existen sujetos como los crackers o hackers que pueden interceptar los mensajes enviados por correo electrónico e inclusive activar el acuse de recibo correspondiente, con lo cual el destinatario recibirá en su computadora el respectivo acuse de recibo que le indicará un dato falso: que el destinatario ha leído su mensaje. En esta medida, consideramos necesario que la presunción de conocimiento siga siendo juris tantum para la formación de cualquier contrato, a fin de permitir al oferente oponerse a su celebración, cuando sin su culpa ha estado imposibilitado de conocer la aceptación. Desde luego, la prueba de ello debe recaer necesariamente en el sujeto que alega la falta de conocimiento. 
Frente a esta incertidumbre e inseguridad de que las declaraciones contractuales no lleguen a su destino o sean adulteradas, la tecnología ha creado técnicas y procedimientos de seguridad como son las firmas electrónicas y los certificados digitales. Mediante estos sistemas se garantiza la integridad y autenticidad de los mensajes electrónicos (oferta, aceptación). En efecto, está demostrado que el sistema de criptografía asimétrica que utilizan las firmas digitales generan una mayor seguridad en el envío de mensajes electrónicos, por lo que se recomienda el uso de estos mecanismos en el comercio electrónico a fin de garantizar seguridad técnica en el intercambio de mensajes electrónicos y con ello, seguridad jurídica en las transacciones comerciales y financieras.

Sin embargo, esta solución se circunscribe a la contratación privada en el territorio peruano, ya que si el contrato es de carácter internacional seguimos con el problema de las distintas leyes que tiene cada país en materia de formación del contrato.

Hoy en día, los peruanos no tendrán problema para contratar por medios electrónicos, pues utilizando el sistema de acuse de recibo se puede determinar el momento de la formación del contrato, y respecto al lugar de la formación del contrato, éste será el del domicilio del oferente. Empero, en materia de comercio exterior, es decir, en el comercio electrónico entre contratantes que domicilian en países distintos, entre un contratante en el Perú y el otro contratante en China, Grecia o Francia, ¿qué principios y qué reglas aplicamos?.

Ya no estamos en el supuesto al que hacía referencia Delia Revoredo, es decir, el contrato donde las partes van a determinar la ley aplicable a su relación contractual antes de obligarse. Esto es factible cuando los contratantes, peruano y chino, celebran uno o dos contratos al año y en consecuencia, discuten su contenido negociando cada una de sus cláusulas, pero en el comercio electrónico la situación es distinta. El éxito del tráfico electrónico es la masificación contractual, por lo tanto no hay tiempo para las discusiones contractuales, sin que por ello no se vayan a dar, pero la regla es la contratación masiva, estandarizada o predispuesta. Algunos dirán que los predisponentes del esquema contractual establecerán la legislación aplicable. Pero si no lo hacen, ¿qué legislación se aplica?.

En este sentido, nuestra posición está orientada a postular la incorporación en todos los países de reglas comunes en temas como la formación del contrato; o en su defecto, la suscripción de un Tratado o Convención sobre Comercio Electrónico a efecto de viabilizar el comercio electrónico 
y la contratación por medios electrónicos, tomando como base la Ley Modelo de UNCITRAL de 1996, debiendo incorporarse en forma homogénea en cada uno de los países que desee reducir las dificultades que el fenómeno de la globalización ha generado y que el comercio electrónico, en materia de contratación, ha multiplicado.

\section{El rol de la autonomía privada, la libertad de formalidad, la buena fe contractual y la confianza en el comercio electrónico}

Como es sabido, la autonomía privada es la facultad que tienen las personas para autorregular sus intereses por autorización expresa del Estado, quien otorga validez y eficacia a las relaciones jurídicas de los particulares, siempre que no atenten contra el orden público, las buenas costumbres o las normas legales de carácter imperativo.

Sobre la base de la autonomía privada o de la voluntad, las personas ejercen su derecho a la libertad de contratación, por lo que la autonomía privada se encuentra íntimamente ligada a la libertad. En efecto, la autonomía privada reposa en tres clases de libertades, la libertad de contratar, la libertad contractual y la libertad como objeto del contrato.

La libertad de contratar o de autorregulación, es la facultad que tienen las personas para contratar o no, y si deciden contratar, elegir al otro contratante.

La libertad contractual o de configuración interna, es la facultad que tienen las personas, una vez que han decidido contratar, determinar libremente el contenido del contrato, es decir, el conjunto de condiciones que regularán la relación jurídica contractual. Sobre la base de esta libertad, los contratantes eligen la categoría contractual, típica o atípica, y las cláusulas que darán vida al contrato.

La libertad como objeto del contrato implica que los contratantes no podrán celebrar contratos que atenten contra la libertad propiamente dicha o contra la esencia e integridad del ser humano, como por ejemplo, que uno sea esclavo del otro, el alquiler de vientre, o la venta de órganos.

La autonomía privada, la libertad de contratar y la libertad contractual son categorías jurídicas que se encuentran reconocidas y regulas por el ordenamiento jurídico peruano y mundial, estableciéndose que la libertad de contratación es un derecho fundamental de toda persona. En tal sentido, las personas somos libres para contratar y libres también para determinar el contenido del contrato, con lo cual podremos decidir cómo 
contratamos, cuándo contratamos, por qué medio contratamos y qué legislación se aplica a nuestras relaciones internacionales.

Sin lugar a dudas, la autonomía privada soluciona en parte la problemática del comercio electrónico, en la medida que las personas tienen la libertad de contratación para poder elegir el medio idóneo para manifestar sus declaraciones contractuales, así como la libertad para elegir la formalidad del contrato, desde luego, respetando siempre las limitaciones legales impuestas por el Estado.

Empero, no basta la autonomía privada, se requiere que en el comercio electrónico exista confianza en el contenido de las ofertas, confianza en el buen funcionamiento de los bienes, confianza en la prestación de los servicios, confianza en la entrega de los bienes y servicios prometidos, en general, confianza en el tráfico comercial. Como señala Roxana Jiménez, esta confianza -que va a generar una razonada creencia en las afirmaciones de la otra parte (lo que se denomina buena fe subjetiva)-, sólo se logrará si la contraparte actúa de buena fe, es decir, si se comporta leal y honestamente (este es el aspecto activo de la buena fe, un deber de conducta, denominado buena fe objetiva) en cada una de sus relaciones contractua$\operatorname{les}^{38}$. No me estoy refiriendo únicamente a los contratantes peruanos, o a los chinos, o a los argentinos, o a los españoles, me refiero a todos los contratantes del planeta, pues todos saben, intuyen o sienten lo que es la buena fe y todos saben y comprenden que solamente un sistema de confiabilidad logrará que el comercio electrónico sea una realidad en potencia.

Mientras esperamos la ansiada confianza y el comportamiento de buena fe de los contratantes en toda la formación del contrato (tratativas o negociación, celebración o conclusión y ejecución) debemos recurrir a sistemas que garanticen el cumplimiento de las obligaciones que los contratantes asumen en los contratos. Este sistema no es otro que la intervención de terceros, la remisión a tribunales jurisdiccionales supranacionales o mundiales, para lo cual urge contar con una legislación uniforme en materia de comercio electrónico.

38 Cfr. Roxana Jiménez Vargas-Machuca, "La unidad del principio general de la buena fe y su trascendencia en el derecho moderno", en Contratación Privada. Contratos Predispuestos. Contratos Conexos. Código Europeo de Contratos», obra colectiva coordinada por Roxana Jiménez y Carlos Soto, a publicarse por la Editorial Temis, Bogotá, 2001. 


\section{El derecho civil frente al auge del comercio electrónico}

La aparición y el auge del comercio electrónico constituye, sin lugar a dudas, una clara señal de que la contratación paritaria (donde los contratantes negocian el contenido del contrato) es una excepción y que la regla en el intercambio de bienes y servicios es la contratación masiva, la contratación predispuesta, la contratación estandarizada.

En efecto, hoy en día, aproximadamente más del $50 \%$ de las personas contratan sin discutir las condiciones de los contratos. En la contratación por medios electrónicos, la masificación contractual es mucho más notoria y evidente. En este sentido, creemos que la autonomía privada debe ser enfocada desde dos perspectivas: para los contratos paritarios se debe respetar los pactos de los contratantes, y en los contratos masivos o predispuestos el Estado debe proteger a la parte más débil (que no necesariamente tiene que ser el deudor, sino el contratante que no ha podido discutir las condiciones del contrato, pero siempre y cuando las condiciones predispuestas sean abusivas o desnaturalicen la relación jurídica contractual).

En consecuencia, persistimos en nuestra tesis de que la teoría general del contrato debe estar orientada a incorporar ambos sistemas de contratación ${ }^{39}$, el sistema paritario y el sistema predispuesto, encontrándose mayoritariamente la contratación por medios electrónicos en el segundo sistema, con la salvedad que las partes contratantes también pueden celebrar contratos por medios electrónicos dentro del sistema negociado o paritario.

Cuando apareció el teléfono en el siglo XIX, la doctrina se preocupó por el uso de este instrumento en la contratación, tan es así que reconocidos tratadistas dedicaron sendos capítulos a la contratación por teléfono, pues estaban preocupados, con justa razón, respecto a que si la contratación por este medio constituía una contratación entre ausentes o entre presentes o una forma especial.

39 Cfr. Carlos Alberto Soto Coaguila, "La transformación del contrato: del contrato negociado al contrato predispuesto», en: Atilio Aníbal Alterini, José Luis de los Mozos y Carlos Alberto Soto; Instituciones de Derecho Privado - Contratación Contemporánea, Op. cit., Volumen 2, pp. 369-438; y, "La contratación contemporánea, el respeto a la autonomía privada y la protección a los contratantes débiles», en Revista Jurídica del Perú, Trujillo, Editorial Normas Legales, junio 2001, Año LI, No 2, pp. 65-77. 
De igual manera las legislaciones más prestigiosas y que sirvieron de fuente para el codificador peruano de 1936 así como para el de 1984, incorporaron en los respectivos códigos civiles normas que señalaban expresamente que la contratación por teléfono era una contratación entre ausentes y por lo tanto válida y eficaz.

\section{Mencionaré algunos casos:}

El Código Civil alemán de 1900, en su numeral 147 señala: «La oferta hecha a una persona presente sólo puede ser aceptada inmediatamente. Esto vale también de una oferta hecha de persona a persona por medio del teléfono».

El Código de las Obligaciones suizo, en el artículo $4^{\circ}$ señala que "Los contratos concluidos por teléfono se les considera hechos entre presentes, si las partes o sus mandatarios han estado han estado personalmente en comunicación».

El Código Civil de Brasil en el artículo $1081^{\circ}$ dispone que a la persona que contrata por teléfono se le considera presente.

El Código Civil de México en el artículo $1805^{\circ}$, el Código Civil de Polonia en el artículo 63․ Código Civil de Bolivia en el artículo $462^{\circ}$, el Código Civil de Etiopía en su artículo $1692^{\circ}$ y el Código Civil peruano de 1936 en su artículo $1330^{\circ}$, consideran como presente a la persona que contrata con otra por teléfono.

En resumen, todas las legislaciones de finales del siglo XIX y comienzos del siglo XX, no sólo dedicaron artículos expresos a la contratación por teléfono, sino que además los propios tratadistas analizaron el problema jurídicamente, inclusive hasta la década de los ochenta se aludía a la contratación por teléfono.

No obstante, con el transcurso del tiempo, la contratación por teléfono fue tan común y ya no presentaba problemas que, por ejemplo, en el Código Civil de 1984 ya no se hace mención a la contratación por teléfono. Será tal vez por que hoy en día la gente contrata habitualmente por este medio. De la misma forma, los modernos proyectos no se refieren al contrato por teléfono, ya que no presenta problema alguno. ¿Qué ha ocurrido?. ¿Por qué las legislaciones y la doctrina autoral ya no se refieren a la contratación por teléfono?. Tal vez la respuesta se deba a que nunca presentó problemas, sino que fueron los juristas los que por tradición legislativa de los Códigos más importantes de la época y por la novedad 
del sistema telefónico decidieron incorporar normas expresas, o porque si presentó algunos convenientes, éstos fueron solucionados oportunamente. A la fecha, es aceptado que el contrato por teléfono es un medio que permite celebrar innumerables contratos y por lo tanto es absurdo que la ley se refiera a él, más aun cuando la sociedad ha aceptado este mecanismo de tal forma que nadie discute la validez y eficacia de un contrato celebrado por este medio.

Nos preguntamos si ocurrirá lo mismo con la contratación por medios electrónicos. El tiempo nos dará la respuesta. Tal vez, en materia contractual, estas discusiones y las largas páginas escritas sobre la contratación por medios electrónicos constituyan de aquí a algunos años temas históricos referidos a la aparición y al auge del comercio electrónico, como hoy nos referimos a la contratación por teléfono. O tal vez la respuesta sea distinta. Por el momento debemos preocuparnos de los problemas que existen y analizarlos de una manera crítica, pero a la vez profunda, sin caer en exageraciones y predicciones sin sentido.

Otro hecho similar a la invención del teléfono, fue la aparición de los cajeros automáticos de las entidades financieras y bancarias. En el Perú, los cajeros automáticos aparecieron en la década de los ochenta. Lo cierto es que cuando se instalaron estas enormes máquinas electrónicas para retirar, depositar o realizar transacciones sin tener que acudir al establecimiento bancario y evitarse las largas colas, la gente desconfiaba de su uso, pues se preguntaban qué seguridad tendrían de que el retiro efectuado iba a ser registrado en su cuenta adecuadamente y de no ser así, cómo reclamarían si no contaban con la constancia que usualmente colocaba el banco en sus libretas de ahorros. En buena cuenta, la desconfianza evitó que en sus inicios se utilizasen los cajeros automáticos.

En la actualidad, un vasto sector de personas no prescinde de un cajero automático. Casi todos de una u otra forma acudimos a un cajero automático. Inclusive las empresas privadas y públicas depositan los salarios en una cuenta bancaria abierta para tal fin a nombre del trabajador, quien ya no tiene que realizar sus cobros a fin de mes en la empresa, sino pasar por el cajero y retirar su sueldo correspondiente. No obstante el uso masificado de los cajeros automáticos, todavía no existe una confianza total de los servicios que brindan estos aparatos electrónicos, pues si bien todos sus usuarios retiran dinero, la gran mayoría, todavía no realiza depósitos de dinero en efectivo, sino que prefieren hacer las colas en los respectivos bancos y depositar sus ahorros directamente en ventanilla. ¿A 
qué se debe este hecho?. Sin lugar a dudas, a la falta de confianza plena de que el depósito será registrado adecuadamente como se lograría en una ventanilla. Desde luego, serán las entidades bancarias y financieras las encargadas de generar confianza en el público usuario respecto de la seguridad de los servicios de depósitos de dinero en los cajeros automáticos y una vez que lo logren, las personas terminaremos utilizando este servicio de modo natural.

Estamos asistiendo y a la vez somos protagonistas de una nueva era mundial que ha sido denominada de diversas formas, tales como postindustrial (Kahn-Wiener, Bell), postmoderna (Enzioni), tecnológica (Ellul), tecnotrónica (Brzezinski), neoindustrial (Valaskakis), superindustrial de la tercera ola (Toffler), de la información (Naisbitt), de la aldeal global (McLuhan), de las redes (Bressand-Distler), sociedad de la información, sociedad de consumo, entre otras muchas más. Solamente la historia determinará que significa está etapa en la historia de la humanidad. Lo cierto es que todo está cambiando. Las actuales estructuras de la sociedad se están resquebrajando en algunos casos y cambiando en otros; por lo tanto, urge que los integrantes de la sociedad reflexionen en torno a los paradigmas ${ }^{40}$ que la sostienen.

Parafraseando a Tomas Kuhn, consideramos que cuando las instituciones vigentes han dejado de resolver con eficacia los problemas planteados por un nuevo contexto es que se produce una revolución científica ${ }^{41}$, la misma que conlleva al rompimiento de los paradigmas existentes.

Por tanto, no le falta razón a Luis Diez-Picazo, cuando señala que toda revolución tecnológica e ideológica «[...] comporta el descubrimiento y la generalización de una serie de técnicas y de una serie de ingenios, que son puestos al servicio del hombre, para que, utilizando los bienes mate-

40 Según Kuhn «Un paradigma es lo que los miembros de una comunidad científica comparten y, recíprocamente, una comunidad científica consiste en hombres que comparten un paradigma", en este sentido, los paradigmas se constituyen como "realizaciones científicas universalmente reconocidas que, durante cierto tiempo, proporcionan modelos de problemas y soluciones a una comunidad científican (VerThomas S. Kuhn, La estructura de las revoluciones científicas. Madrid, Fondo de Cultura Económica, 1975, p. 13).

41 Para Kuhn «las revoluciones científicas como episodios evolutivos de carácter no acumulativo en los que un nuevo paradigma, incompatible con el anterior, viene a sustituir al antiguo, total o parcialmente." (Cfr. Thomas S. Kuhn, "Revoluciones en el pensamienton. En: Robert Nisbet, Thomas S. Kuhn, Lynn White y otros. Cambio social. Versión española de Leopoldo Lovelac. Madrid, Alianza Editorial, 1979, p. 144). 
riales y las energías, amplíe y facilite la consecución de sus fines y el ámbito de su libertad" ${ }^{42}$.

En materia de contratación por medios electrónicos el reto es inminente y los juristas deben enfrentar con espíritu crítico esta nueva forma de contratación. En consecuencia, debemos aprehender la problemática actual que nos trae la informática y adecuarla al derecho común vigente para contrastar si los presupuestos contemplados por el derecho vigente le son aplicables o no, pero no debe caerse, en lo que de común sucede cuando aparece un nuevo fenómeno social o tecnológico, en crear reglas especiales cuando basta con las normas ya existentes. Por lo tanto, reafirmamos nuestra posición de que el comercio electrónico o e-commerce sólo será una realidad en todo el mundo si existe la confianza necesaria en todos los agentes económicos que participan en el intercambio de bienes y servicios (Estado, empresa y consumidor). Ellos son los que deben crear los mecanismos de seguridad y generar la confianza suficiente de que su uso no creará problemas a los usuarios. Sólo mediante una confianza adecuada y con costos de transacción atractivos que generen mayores beneficios será posible el uso y la masificación del comercio electrónico. En tal sentido, rechazamos categóricamente las políticas de gobierno tendientes a regular en forma reglamentaria el fenómeno del comercio electrónico, por lo menos en materia de contratación, pues por más voluntad que exista lo único que se logrará será un rechazo de los agentes económicos internacionales, si tal regulación incrementa los costos de transacción dificultando el acceso mediante requisitos innecesarios.

Muy frecuentemente somos testigos o hasta hemos manifestado que son los jueces los culpables de la inercia del Derecho, son ellos lo que no interpretan las normas adecuadamente y son ellos los que al momento de dirimir una controversia no recurren a la doctrina autoral y la jurisprudencia nacional y comparada, limitándose únicamente a la aplicación literal de la ley. En cierta medida es válida esta crítica, ya que prueba de ello lo constituyen las innumerables resoluciones judiciales que carecen de una motivación razonada y calificada. Sin embargo, plantear el problema de esta forma es mirar solamente uno de sus lados, pues los abogados también somos responsables de la inercia del Derecho, ya que no debemos olvidar que los jueces resuelven sobre la base de la demanda y la contestación que presentan los abogados.

42 Véasc Luis Diez-Picazo, Experiencias Jurídicas y Teoría del Derecho. Barcelona, Editorial Ariel, 1982, p. 301. 
Para terminar, sólo resta decir que la transformación del derecho está en manos de aquellas personas que tienen el coraje de soñar en una sociedad justa, donde reine la justicia, la seguridad jurídica y el bien común. ¿Cuántos estamos dispuestos o somos valientes para correr el riesgo de vivir tales sueños...? 